\title{
Claude Lévi-Strauss
}




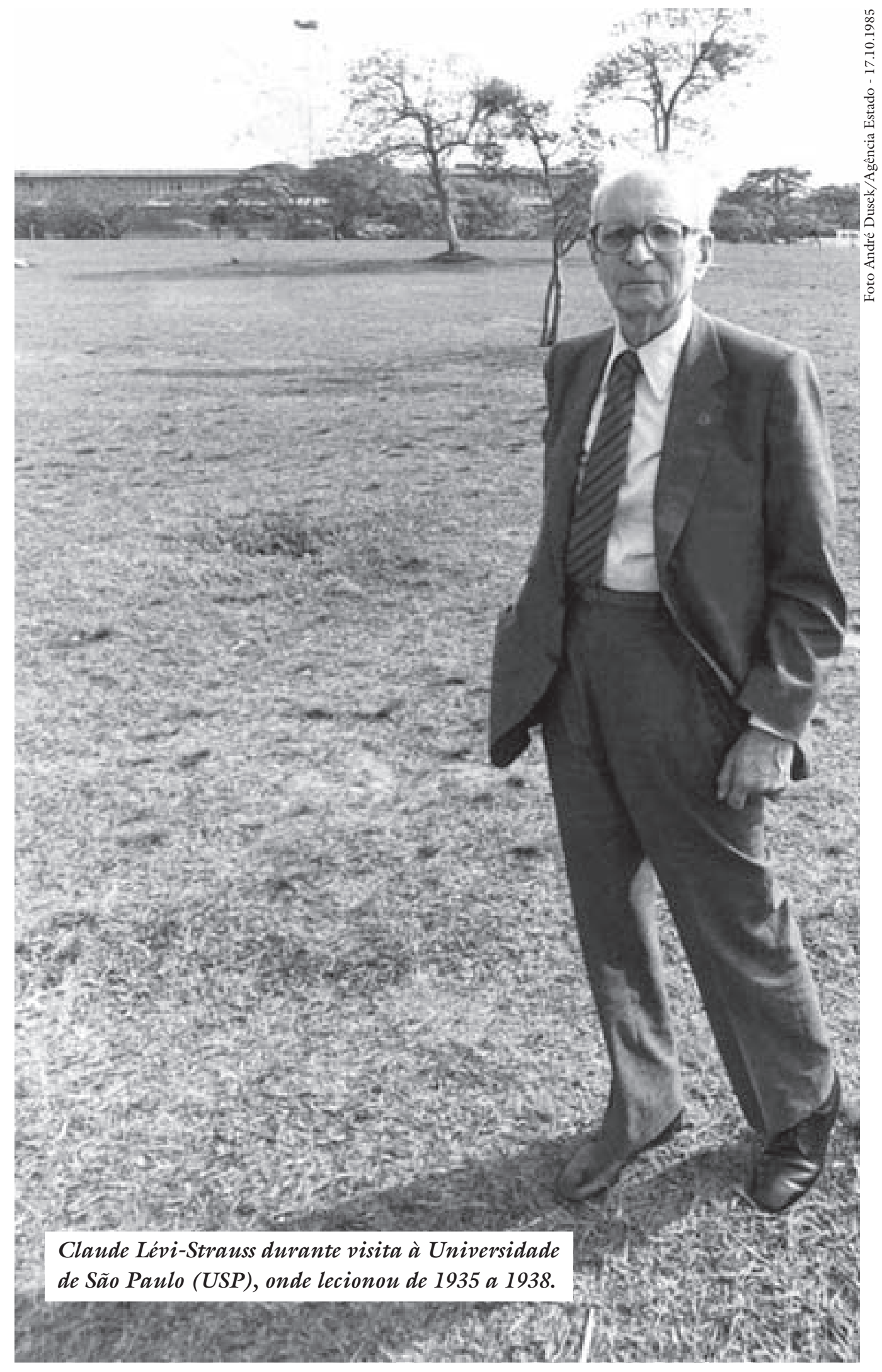




\title{
Claude Lévi-Strauss,
}

\section{uma apresentação ${ }^{1}$}

\author{
PHILIPPE DESCOLA
}

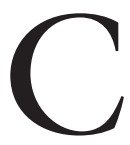

LAUDE LÉVI-STRAUSS é, sem dúvida, o antropólogo cuja obra terá exercido a maior in uência no século XX. Seu nome é indissociável do que foi chamado, depois dele, antropologia estrutural. Entre as múltiplas abordagens que o campo das ciências sociais conheceu no século XX, essa ocupa uma posição particular: nem releitura ousada de um sistema explicativo já reconhecido, nem teoria regional de uma classe de fenômenos circunscritos, a antropologia estrutural é primeiramente um método de conhecimento original, forjado no tratamento de problemas particulares a uma disciplina, mas cujo objeto é em princípio tão vasto e a fecundidade tão notável que ele rapidamente exerceu uma in uência muito além do campo de pesquisa que o viu nascer. Raramente também um modelo de análise do fato social terá sido tão intimamente confundido com a pessoa do seu criador, a ponto de o estruturalismo antropológico poder ser visto às vezes como um sistema de pensamento rebelde a toda aplicação por outros que não aquele que esteve em sua origem. Lévi-Strauss formula seus princípios desde a primeira temporada nos Estados Unidos, após sua descoberta da linguística estrutural e dos trabalhos de N. Trubetzkoy e de R. Jakobson (conhecido em Nova York, este último se tornará um amigo). Desde essa época, com efeito, ele está convencido de que a etnologia deve seguir o mesmo caminho que a linguística se quiser adquirir o estatuto de uma ciência rigorosa (Lévi-Strauss, 1945; 1958, cap.II). Por sua vez, convencido muito cedo pelo convívio com suas "três amantes" - Freud, Marx e a geologia - de que a ciência social não se constrói a partir da realidade manifesta, mas sim elucidando a ordem inconsciente na qual se revela a adequação racional entre as propriedades do pensamento e as do mundo, ele descobre na fonologia um modelo exemplar para pôr em prática sua intuição. Esse modelo apresenta quatro características importantes: abandona o nível dos fenômenos conscientes para privilegiar o estudo de sua infraestrutura inconsciente; dão-se por objeto de análise não os termos, mas as relações que os unem; procura mostrar que essas relações formam sistema; enfim, busca descobrir leis gerais. Desde essa época, Lévi-Strauss lança a hipótese de que esses quatro procedimentos combinados podem ajudar a esclarecer os problemas de parentesco em razão da analogia formal que ele descobre entre os fonemas e os termos que servem para designar os parentes. Ambos são elementos cuja significação provém do fato de estarem combinados em sistemas, eles próprios produtos do funcionamento inconsciente do espírito, e cuja recorrência em muitos lugares do mundo sugere que respondem a leis universais. 
Todas as ideias-força da antropologia estrutural já estão presentes nesse esboço, incluindo o conceito de troca, oriundo de uma outra herança intelectual, a do Ensaio sobre a dádiva de Marcel Mauss, e que terá um papel importante em As estrutura elementares do parentesco. No início desse livro, com efeito, LéviStrauss afirma que a proibição do incesto deve ser vista como o avesso universal e negativo de uma regra de reciprocidade positiva que exige a troca das mulheres nos sistemas de aliança matrimonial. Essa perspectiva renovava radicalmente a abordagem dos fenômenos de parentesco, abandonando o ponto de vista da sociologia dos modos de filiação e dos princípios de constituição dos grupos de descendência, assim como o de sua reconstrução histórica conjetural, nos quais se confinavam até então o funcionalismo e o evolucionismo. Ela os substituía por uma teoria geral da aliança de casamento que esclarece, por sua vez, a natureza e o funcionamento das unidades sociais em jogo no parentesco - clãs, linhagens, grupos exógamos - ao mesmo tempo que os recoloca num conjunto mais amplo. Além disso, fundava a generalidade e a recorrência das regras que ordenam os sistemas de troca matrimonial sobre as estruturas do espírito, única base lógica capaz, segundo Lévi-Strauss, de garantir o postulado da unidade do homem na diversidade de suas produções culturais. Comprova-o a organização dualista um sistema extremamente comum no qual os membros da comunidade se dividem em duas metades que mantêm toda uma gama de relações complexas de interdependência. A instituição revela claramente os mecanismos classificatórios do parentesco - cada um se define pelo pertencimento à sua metade - e, mais do que isso, o papel crucial do princípio de reciprocidade, do qual a organização dualista aparece como a realização mais direta, mas que pode igualmente se encarnar em múltiplas outras formas de vida social. Entre todas essas formas, afirma Lévi-Strauss, há diferença de grau e não de natureza, pois sua base comum repousa sobre estruturas fundamentais do espírito humano: o princípio de reciprocidade, a exigência da regra como regra e o caráter sintético da dádiva, isto é, o fato de que a transferência consentida de um valor, de um indivíduo a outro, transforma esses em parceiros e acrescenta uma qualidade nova ao valor transferido (Lévi-Strauss, 1949, p.108). Portanto, em última instância, é na natureza do homem, em esquemas formais e universais profundamente inscritos no seu espírito, mas sempre conscientemente apreendidos, que reside o fundamento das instituições matrimoniais e, de maneira mais ampla, da própria cultura, cuja emergência é marcada pela proibição do incesto. Uma tal profissão de fé é idealista apenas em aparência, pois desde As estruturas elementares do parentesco, e ao longo de toda a sua obra, Lévi-Strauss se diz convencido de que as leis do pensamento não diferem das que ocorrem no mundo físico e na realidade social que não é senão, ela mesma, um de seus aspectos.

O título que Lévi-Strauss deu à sua direção de estudos na VI âa seção da École Pratique des Hautes Études (EPHE), quando retornou à França, é o mesmo que ele adotou mais tarde para a sua cadeira no Collège de France, "antropologia social". A escolha desses termos define bem a mudança de perspectiva 
que ele trouxe aos estudos etnológicos. Embora empregada havia décadas nos países anglo-saxões, a expressão "antropologia social" era inusitada na França logo depois da guerra; evocadora do projeto universalista próprio às antropologias filosóficas, ela implicava também uma hierarquia dos modos e dos objetos de conhecimento, dos quais a etnografia e a etnologia são os outros termos, não segundo uma ordem de dignidade decrescente, mas em razão de sua articulação interna nas diferentes etapas do procedimento científico (cf. Lévi-Strauss, 1958, p.386-9). Analítica e descritiva, a etnografia corresponde aos primeiros estágios da pesquisa: é a pesquisa de campo e a coleta dos dados mais diversos sobre uma sociedade particular, que em geral resulta num estudo monográfico circunscrito no tempo e no espaço. A etnologia prolonga a etnografia e representa um primeiro esforço de síntese visando a generalizações suficientemente amplas num nível regional (conjunto de sociedades vizinhas que apresentam afinidades) ou temático (atenção voltada a um tipo de fenômeno ou de prática comum a numerosas sociedades), para que o recurso a fontes etnográficas secundárias seja um pré-requisito obrigatório, e a manifestação de propriedades comparáveis, o resultado esperado. Mais raramente bem-sucedida, a antropologia representa o último momento da síntese: sobre a base dos ensinamentos da etnografia e da etnologia, ela aspira a produzir um conhecimento global do homem, descobrindo os princípios que tornam inteligível a diversidade de suas produções sociais e de suas representações culturais ao longo dos séculos e através dos continentes.

Apesar, porém, do título de suas aulas na VI ${ }^{a}$ seção, Lévi-Strauss tenderá a privilegiar, a partir da segunda metade dos anos 1950, a antropologia cultural em vez da antropologia social. Fiel ao seu projeto de fazer um inventário das "muralhas mentais" a partir da experiência etnográfica, e convencido de que a antropologia é em primeiro lugar uma psicologia, ele abandonará progressivamente o campo dos estudos sociológicos para se dedicar ao estudo das diferentes manifestações do pensamento mítico. De fato, nada garante que as restrições observadas nos sistemas de parentesco sejam de origem mental; elas talvez sejam apenas um re exo, na consciência dos homens, de "certas exigências da vida social objetivadas nas instituições" (Lévi-Strauss, 1964, p.18). A mitologia não apresenta essa ambiguidade, pois não tem nenhuma função prática, e assim revela ao analista, de uma forma particularmente pura, as operações de um espírito não mais condenado a pôr em ordem uma realidade que lhe é exterior, mas livre para compor consigo mesmo, como por desdobramento. Os trabalhos sobre o "pensamento selvagem" constituem uma etapa intermediária nessa tentativa de remontar sempre mais em direção às leis inconscientes do espírito. Os sistemas de classificação e as operações rituais das sociedades sem escrita referem-se a objetos, geralmente naturais, e a suas presumidas conexões, mas tornam igualmente manifestas operações mentais (classificação, hierarquização, causalidade, homologia...) que não diferem, no fundo, das do pensamento científico, mesmo se os fenômenos aos quais se aplicam e os conhecimentos que produzem as fazem parecer muito distantes dessas. De fato, o pensamento selvagem se exerce primeiramente sobre 


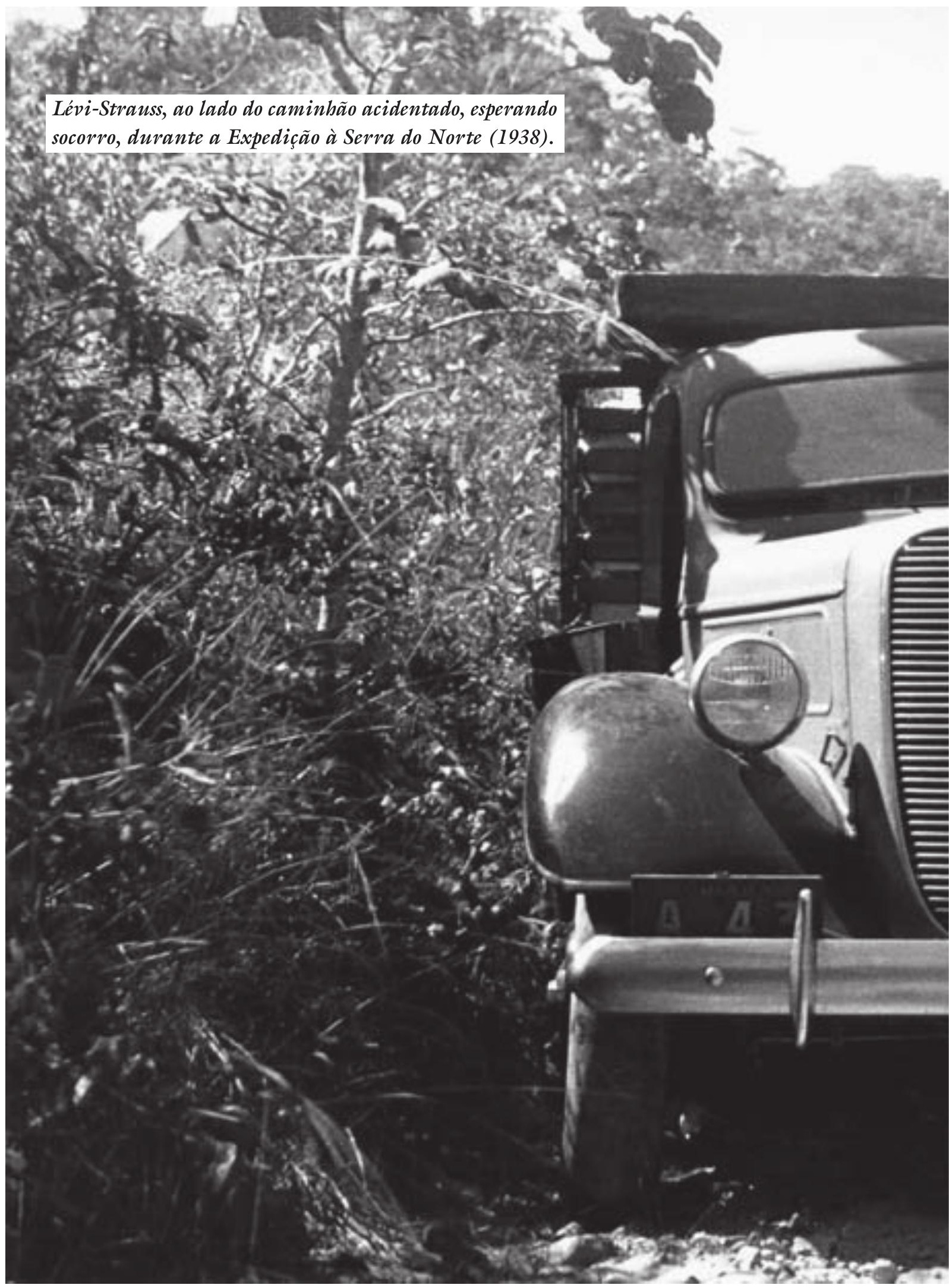


as categorias sensíveis, desencavando e ordenando os caracteres visíveis mais significativos dos objetos para convertê-los em signos de suas propriedades ocultas. À diferença dos conceitos abstratos que a ciência utiliza, esses signos estão ainda presos às imagens das quais tiram sua existência, mas já possuem um grau suficiente de autonomia em relação a seus referentes para poder ser empregados, dentro de seu registro limitado, com fins diferentes daqueles a que se destinavam no início. A lógica do sensível é assim uma "bricolagem intelectual" que explora um pequeno repertório de relações permutáveis no interior de um conjunto que forma sistema, e tal que a modificação de um de seus elementos interessará necessariamente todos os outros. A análise estrutural, portanto, não tem apenas por ambição elucidar a lógica oculta em operação no pensamento mítico; o que ela busca, por meio do estudo do "pensamento dos selvagens", é esclarecer aquela parte de "pensamento em estado selvagem" que cada um de nós conserva como um resíduo anterior à grande domesticação racional.

Em 1959, Claude Lévi-Strauss é eleito professor no Collège de France graças à intervenção decidida de Maurice Merleau-Ponty. Essa consagração sanciona uma obra já então reconhecida e admirada por um largo círculo de cientistas e intelectuais ao redor do mundo, mas mostra também, em sentido contrário, a resistência da universidade tradicional em acolher no seu seio pesquisas que se afastam demais da ortodoxia. A retomada do título "antropologia social" não assinala, porém, um retorno aos problemas sociológicos. O período que se inaugura será na verdade marcado pelo estudo dos mitos e resultará na publicação, escalonada em oito anos, dos quatro volumes das Mitológicas, cuja matéria é fornecida pelas aulas no Collège de France. Mais ainda que outros produtos do pensamento selvagem, os mitos parecem o fruto de uma liberdade criadora totalmente desligada das restrições do real; esclarecer suas leis de funcionamento deveria permitir, portanto, remontar mais acima na compreensão de um espírito que se toma a si mesmo como objeto, sem que os sujeitos falantes tenham consciência da maneira como ele procede. Pois cada mito, tomado separadamente, é uma história disparatada, sem verdadeira significação a não ser a lição moral que os que o contam se julgam às vezes autorizados a tirar. É que o sentido não procede do conteúdo deste ou daquele mito abusivamente privilegiado, mas da ressonância de milhares de mitos que, para além da diversidade aparente de seus conteúdos e do afastamento das populações que os elaboraram, tecem ao redor do mundo uma trama lógica em perpétua transformação e cujas múltiplas combinações desenham o campo fechado das operações do espírito humano. Assim, a análise estrutural dos mitos não poderia pretender uma exaustividade, pois, progredindo ao sabor das associações de uma cadeia sintagmática a partir de um mito de referência arbitrariamente escolhido, ela só pode aspirar a reconhecer, nessa trama imensa, matrizes de significação fragmentadas que um outro caminho talvez tivesse ignorado. Relato de um itinerário pela terra redonda dos mitos mais do que geografia universal de suas redes, as Mitológicas convidam a retomar uma viagem que o próprio Lévi-Strauss não deixou de prosseguir. 
A obra científica considerável de Lévi-Strauss não deve fazer esquecer a importância de sua re exão moral: denunciando sem trégua o empobrecimento conjunto da diversidade das culturas e das espécies naturais, ele sempre viu na antropologia um instrumento crítico dos preconceitos, sobretudo raciais, ao mesmo tempo que um meio de aplicar um humanismo "generalizado", ou seja, não mais, como no Renascimento, limitado apenas às sociedades ocidentais, mas que leve em conta a experiência e os saberes do conjunto das sociedades humanas passadas e presentes. Longe de conduzir a uma improvável civilização mundial que abole as singularidades, esse humanismo afirma, ao contrário, que, em matéria estética e espiritual, toda criação verdadeira impõe, tanto a um indivíduo como a uma cultura, buscar nos seus particularismos um meio de melhor contrastá-los com outros valores. Aliás, a questão estética forma um fio condutor no pensamento de Lévi-Strauss, não apenas porque ele considerou as formas de expressão artísticas - ou percebidas como tais - das sociedades não ocidentais ao mesmo tempo como um desafio à racionalidade do Ocidente e um objeto legítimo de saber antropológico, mas também porque sua obra se alimenta de uma re exão profunda sobre o papel da música e da pintura como mediações entre o sensível e o inteligível, o que faz dela uma contribuição de primeiro plano à teoria estética.

A in uência da antropologia estrutural se desenvolveu de diversas maneiras segundo as épocas e o tipo de meio intelectual que atingiu. Ao terminar a guerra, os etnólogos franceses da geração de Lévi-Strauss (Soustelle, Griaule, Leroi-Gourhan) estavam envolvidos em suas próprias obras para sofrer profundamente a in uência de suas ideias; assim, foi antes no estrangeiro, sobretudo na Inglaterra e na Holanda, que essas encontraram de início um eco. $\mathrm{Na}$ França, foram especialmente linguistas (Benveniste, Dumézil), filósofos (Koyré, Merleau-Ponty) e historiadores (Febvre, Braudel, Morazé) que, no começo dos anos 1950, souberam apreciar a originalidade das perspectivas que ele abria. A publicação em 1955 de Tristes trópicos faz um público mais amplo descobrir a originalidade do pensamento de Lévi-Strauss e a prosa de um grande escritor, e ajuda por muito tempo a suscitar vocações para a etnologia. No entanto, a antropologia estrutural stricto sensu não poderia ter outro intérprete legítimo senão o seu fundador, já que ninguém aderiu à totalidade dos postulados, das regras de método e das conclusões que definem a particularidade do empreendimento lévi-straussiano. Em contrapartida, muitos são os pesquisadores franceses que se reconhecem no que poderíamos chamar uma etnologia estruturalista, cuja homogeneidade, aliás, é mais perceptível quando vista do estrangeiro, em razão das especificidades que manifesta em relação a outras tradições antropológicas nacionais. Alguns traços a distinguem, sem que sua soma forme necessariamente um credo compartilhado: a convicção de que a antropologia tem por tarefa elucidar a variabilidade aparente dos fenômenos sociais e culturais trazendo à luz invariantes mínimos, isto é, regularidades recorrentes na organização de sistemas de relações cujo funcionamento obedece na maioria das vezes a regras 


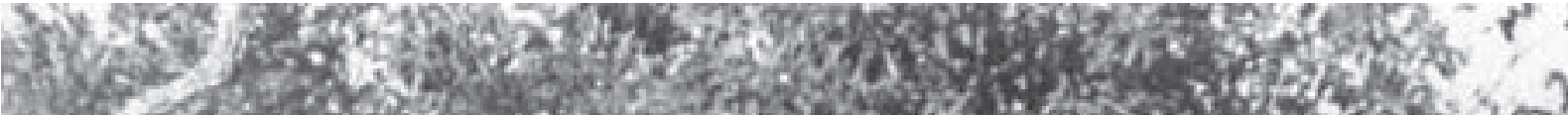

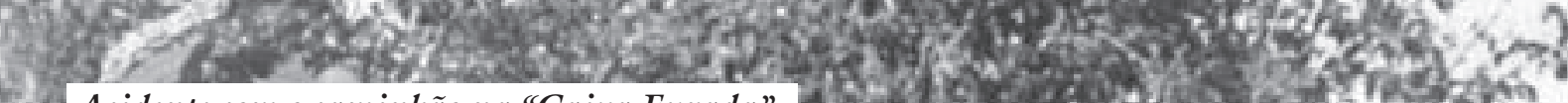

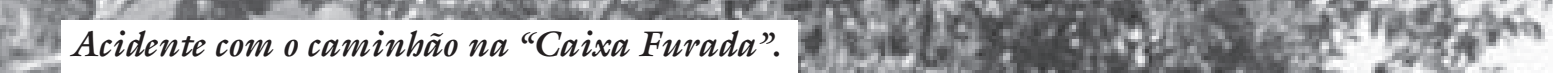
Dinab Lévi-Strauss realiza anotações de campo.

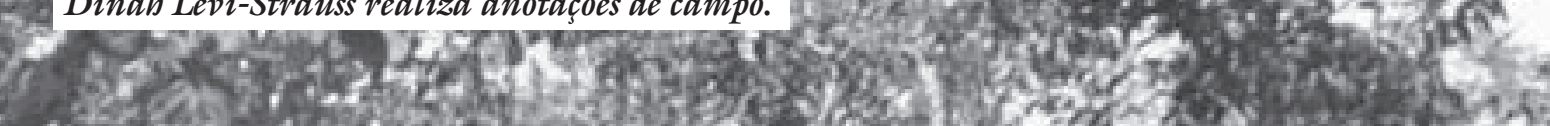

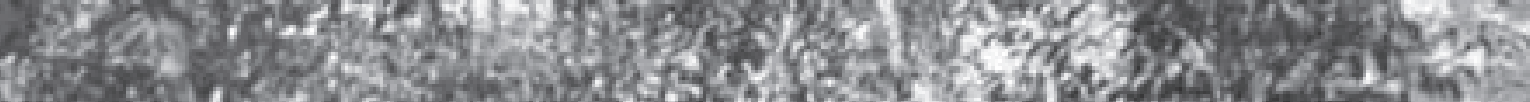
(2)

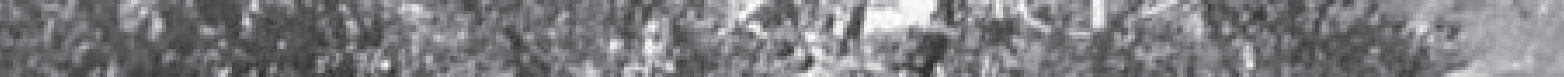

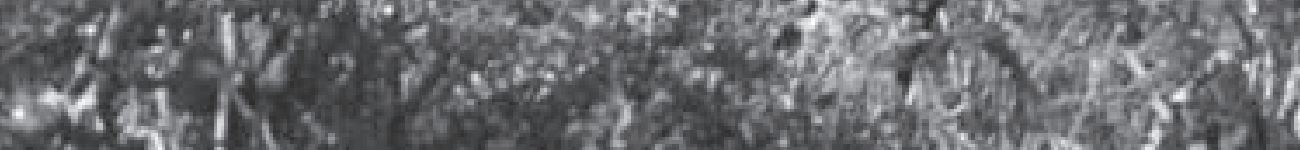
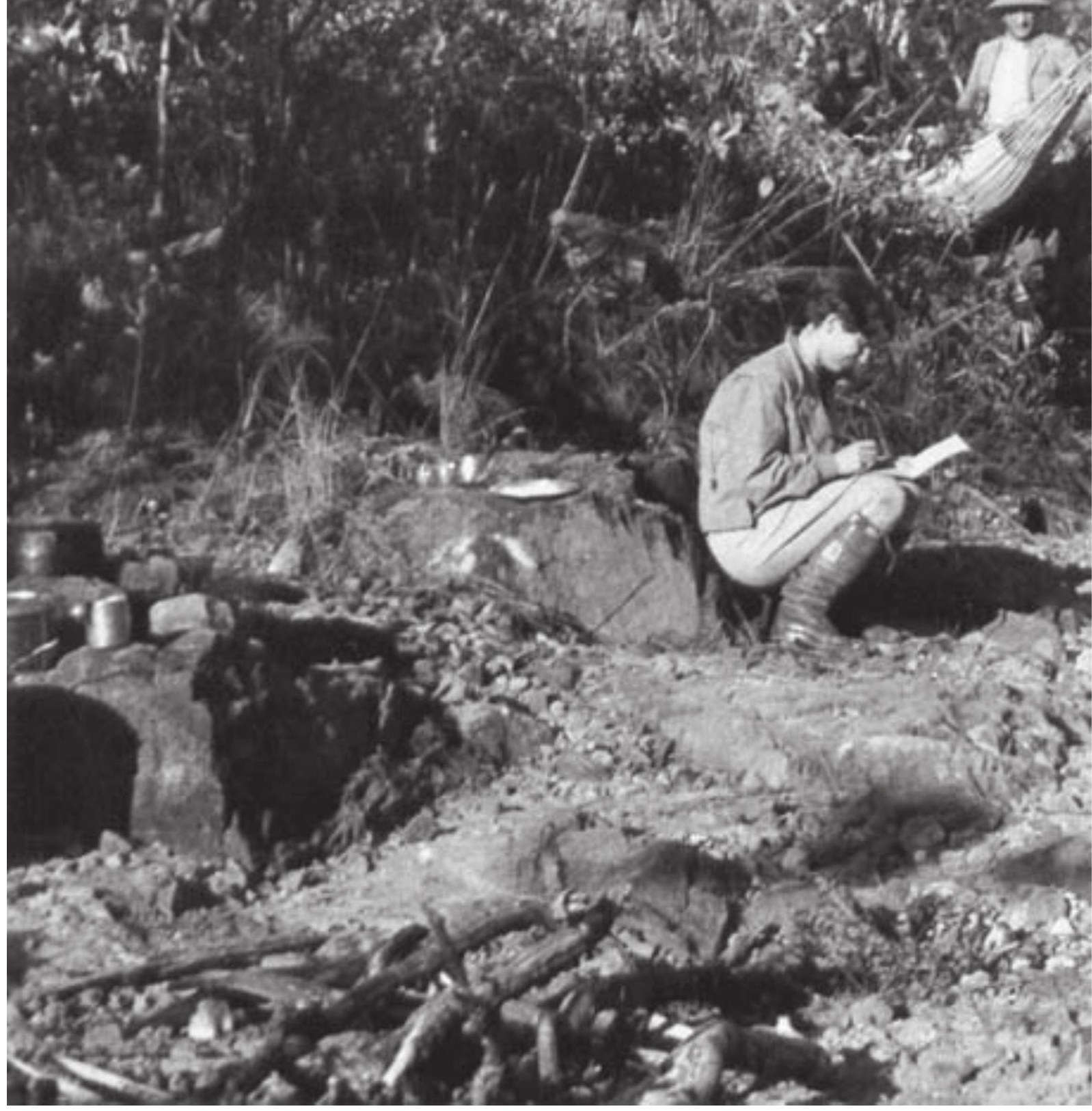
inconscientes; a hipótese de que esses invariantes estão fundados tanto sobre determinações materiais (a estrutura do cérebro, as características biológicas do homem, as modalidades de sua atividade produtiva ou as propriedades físicas dos objetos do seu ambiente) quanto sobre alguns imperativos trans-históricos da vida social; enfim, a precedência dada às análises sincrônicas sobre as análises diacrônicas, não por rejeição de toda dimensão histórica, mas por recusa da posição empirista que consiste em explicar a gênese de um sistema antes de ter definido a sua estrutura.

Enfim, e por ser um método de conhecimento extensível por princípio a qualquer fenômeno social e cultural, a antropologia estrutural também soube encontrar uma audiência fora do campo tradicionalmente coberto pela etnologia. É o caso de alguns filósofos, que acolheram com satisfação um pensamento que recusava o primado da consciência e do sujeito (Merleau-Ponty, Foucault, Althusser, Deleuze). Também o de historiadores, sobretudo os da Antiguidade, os medievalistas e os especialistas em sociedades não europeias, seduzidos tanto pelo método lévi-straussiano quanto pela tentação de apreender seus respectivos objetos com o "olhar distanciado" que o etnólogo utiliza ao pesquisar um povo exótico. É verdade que historiadores como J.-P. Vernant vinham havia muito conduzindo análises inteiramente estruturais e que sua in uência, combinada à de Dumézil e à de Lévi-Strauss, contribuiu de forma decisiva para uma certa "orientação estruturalista” dos estudos sobre a Antiguidade.

Nota

l O presente artigo retoma explanações de trabalho anterior (Descola, 1996).

Referências bibliográficas

DESCOLA, P. Anthropologie structurale et ethnologie structuraliste. In: REVEL, J.; WACHTEL, N. (Org.) Une école pour les sciences sociales. De la VI' section à l'EHESS. Paris: Cerf, Éditions de l'EHESS, 1996. p.127-43.

LÉVI-STRAUSS, C. L'analyse structurale en linguistique et en anthropologie. Word, Journal of the Linguistic Circle of New-York, v.1, n.2, p.1-21, Aug. 1945.

. Les structures élémentaires de la parenté. Paris: PUF, 1949.

. Anthropologie structurale. Paris: Plon, 1958.

. Mythologiques. Paris: Plon, 1964. v.1: "Le cru et le cuit".

Philippe Descola, professor do Collège de France, titular da Cátedra de Antropologia da Natureza desde 2000, foi orientando de Lévi-Strauss. @ - descola@ehess.fr

Publicado em Hors Série - La Lettre du Collège de France, Claude Lévi-Strauss - Centième anniversaire, Novembre 2008. Tradução de Paulo Neves. O original em francês - "Claude Lévi-Strauss, une presentation" - encontra-se à disposição do leitor no IEA-USP para eventual consulta.

Recebido em 16.7.2009 e aceito em 21.8.2009. 


\section{Elementos biográficos}

Claude Lévi-Strauss nasceu em Bruxelas em 28 de novembro de 1908, de pais franceses. Após estudos secundários e superiores em Paris (licenciatura em Direito, agrégation em Filosofia em 1931), é nomeado professor de Filosofia nos liceus de Mont-de-Marsan e depois Laon (1932-1934). Membro da Missão Universitária Francesa ao Brasil (com Fernand Braudel e Pierre Deffontaines, em particular), leciona Sociologia e Etnologia de 1935 a 1938 na recém-inaugurada Universidade de São Paulo (USP) e empreende várias expedições etnográficas ao Mato Grosso e à Amazônia, antes de voltar à França às vésperas da guerra, da qual participa como agente de ligação. Desmobilizado após o armistício e visado pelas leis antissemitas de Vichy, Lévi-Strauss consegue deixar a França e vai para os Estados Unidos, onde leciona na New School for Social Research de Nova York. Engajado como voluntário nas forças francesas livres e designado para a Missão Científica Francesa nos Estados Unidos, funda (com Henri Focillon, Alexandre Koyré e Jacques Maritain, entre outros), a Escola Livre de Altos Estudos de Nova York, da qual será o secretário-geral. Chamado de volta à França em 1944 pelo ministro dos Assuntos Estrangeiros, retorna aos Estados Unidos em 1945 para ocupar as funções de conselheiro cultural junto à embaixada da França. De volta à França em 1948, defende a tese de doutorado sobre As estruturas elementares do parentesco (seu mestrado trata da Vida familiar e social dos indios Nambiquara) e se dedica desde então exclusivamente a seu trabalho científico. Convidado por Lucien Febvre em 1948 para a recém-inaugurada VI $\underline{a}$ seção da École Pratique des Hautes Études (EPHE) (transformada em École des Hautes Études en Sciences Sociales (EHESS), em 1975), tornase o subdiretor do Museu do Homem em 1949 e é nomeado no mesmo ano diretor de estudos na V ${ }^{\mathbf{a}}$ seção da École Pratique des Hautes Études, cadeira de Religiões Comparadas dos Povos sem Escrita. A seguir é professor no Collège de France, na cadeira de Antropologia Social, de 1959 a 1982, ano em que se aposenta. Até essa data dirige o Laboratório de Antropologia Social, que fundou em 1960. Entra para a Academia francesa em 1973. Em 28 de novembro de 2008, completou 100 anos de idade.

\section{Principais obras}

1948 - La vie familiale et sociale des indiens Nambikwara. Paris: Société des Américaniste. 
1949 - Les structures élémentaires de la parenté. Paris-Haia: Mouton \& Co. 1950 - Introduction à l'oeuvre de Marcel Mauss. In: Marcel Mauss. Sociologie et anthropologie. Paris: PUF.

1955 - Tristes tropiques. Paris: Plon. (Collection Terre Humaine).

1958 - Anthropologie structurale. Paris: Plon.

1961 - (1952) Race et histoire. Paris: Gonthier.

1962a - La pensée sauvage. Paris: Plon.

1962b - Le totémisme anjourd'hui. Paris: PUF.

1964 - Mythologiques. Paris: Plon. v.I: "Le cru et le cuit".

1966 - Mythologiques. Paris: Plon. v.II: "Du miel aux cendres".

1968 - Mythologiques. Paris: Plon. v.III. "L'origine des manières de table".

1971 - Mythologiques. Paris: Plon. v.IV: "L'homme nu”.

1973 - Anthropologie structurale deux. Paris: Plon.

1975 - La voie des masques. Genebra: Skira (reedição ampliada, Plon, 1979). $2 \mathrm{v}$.

1983 - Le regard éloigné. Paris: Plon.

1984 - Paroles données. Paris: Plon.

1985 - La potière jalouse. Paris: Plon.

1991 - Histoire de Lynx. Paris: Plon.

1996 - Regarder écouter lire. Paris: Plon. 